\title{
RANCANG BANGUN EVENT SALAAM ORGANIZER SEMARANG BERBASIS WEB MOBILE
}

\author{
Novita Kusuma Wati ${ }^{1}$, Fatkhul Amin ${ }^{2}$ \\ ${ }^{1,2}$ Program Studi Teknik Informatika, Fakultas Teknologi Informasi, Universitas Stikubank \\ e-mail: ${ }^{1}$ knovita@ymail.com, ${ }^{2}$ fakhulamin@edu.unisbank.ac.id
}

\begin{abstract}
Abstrak
Salaam Organizer perusahaan yang bergerak dibidang jasa untuk melayani service wedding. Kendala yang sedang dihadapi Salaam Organizer masih mengunakan cara tradisional untuk promosi, komunikasi, memantau, dan melalukan transaksi pembayaran dengan telepon dan jejaring sosial. Salaam Organizer perlu adanya aplikasi web mobile sebagai media penunjang. Metode yang digunakan dalam implementasi ini menggunakan metode breakdown and weighted. Hasil penelitian yang dibuat, terciptanya sistem aplikasi e-service berbasis web mobile untuk pelayanan jasa wedding dan menjadikan sistem aplikasi yang interaktif dan multifungsi. Sistem yang dibuat nantinya akan memudahkan pelayanan dikantor Salaam Organizer.
\end{abstract}

Kata Kunci: E-Service Wedding, E-Service, Web Mobile

\section{PENDAHULUAN}

Perkembangan web mobile semakin pesat berkembang sejak munculnya teknologi internet yang sangat membantu dalam memudahkan untuk menerima segala informasi. Menggunakan aplikasi mobile, anda dapat melakukan berbagai aktifitas mulai dari berjualan, hiburan, mencari informasi, perkembangan pasar dan lain sebagainya. Pemanfaatan aplikasi mobile ini banyak dimanfaatkan dari berbagai kalangan seperti: orang tua, remaja, anak-anak, dan perkerja. Aplikasi mobile ini sangat berguna sekali bagi pebisnis yang mobilitasnya sangat tinggi dalam perkerjaannya contohnya seorang pembisnis membutuhkan informasi Stock market untuk kelancaran usaha/perkerjaannya, tentu aplikasi mobile disini sangat berperan dalam menunjang mobilitas perkerjaan. Di era ini Sosial media menjadi lifestyle dikalangan remaja. aplikasi yang dibuat untuk mempublikasikan privasi diri seseorang di social network yang orang lain dapat ketahui. (Muhammad, Reno Harahap 2014).

Salaam Organizer merupakan perusahaan dibidang jasa untuk event wedding yang ada di Semarang, beralamat di Jalan Mulawarman I No. 3 Jabungan, Banyumanik, Semarang. Saat ini, Salaam Organizer di pimpin oleh bapak Aris Kurnianto, S.Psi sekaligus direktur Salaam Organizer. Jumlah karyawan yang bekerja di Salaam Organizer sebanyak 10 orang (tetap), 10 orang free lance dan volunteers jika dibutuhkan. Diperoleh hasil bahwa selama proses kinerja yang sudah dilakukan perlu adanya alat penunjang untuk mepermudah menyelesaikan proses tersebut. Sistem yang diterapkan di Salaam Organizer masih tradisional yaitu dengan menggunakan telepon, dan jejaring sosial, namun dengan sistem demikian dirasa masih terdapat kendala, karena masih terdapat client/konsumen yang mengalami kesulitan dalam order maupun mengkontrol orderan yang sudah berjalan (on procces). Hal ini akan menjadi masalah, apabila client tidak memahami apa yang sudah di order maka prosesnya akan terhambat dan pada saat acara menjadi tidak sesuai yang diharapkan karena dengan proses yang rumit tersebut. Selain itu client dapat mengetahui dan dapat mencari informasi terlebih dahulu mengenai how toorder dan memastikan hal yang diinginkan serta mengikuti alur proses yang sudah ditentukan dan yang nantinya akan disepakati bersama oleh kedua belah pihak. Sehingga diperlukan inovasi baru dalam proses pelayanan kepada client untuk menggunakan jasa event wedding agar dapat lebih memahami dan tahu secara jelas.

Faktor yang menjadikan latar belakang untuk membuat sistem yang berguna untuk penyedia jasa kepada client/konsumen yaitu membantu proses berjalannya pelayanan jasa wedding yang membutuhkan waktu yang cukup lama sehingga menyita waktu dengan kesibukan masing-masing orang, maka dari itu dengan adanya sistem tersebut dapat mempermudah untuk mengetahui seberapa jauh perkembangan pemesanan vendor ataupun progres, melihat dan memastikan penjadwalan client 
untuk melakukan pertemuan, melakukan konfirmasi misalnya request untuk penambahan atau pengurangan dalam pemesanan dan juga bisa cancel mengganti vendor, melakukan confirmpayment terhadap pemesanan. Berdasarkan solusi dari permasalahan tersebut diharapkan memberikan kemudahan bagi client/konsumen maupun pihak perusahaan yang terlibat agar efesien dalam melakukan pemesanan untuk pelayanan jasa wedding tersebut dan bisa memanfaatkan perkembangan teknologi yang begitu canggih, semua ini akan menjadi mudah dan dapat dijangkau sekaligus menjadi alternative pihak client karena disamping menghemat waktu dan tenaga juga menghemat biaya untuk setiap kali melakukan pertemuan menghabisakan biaya transport, akomodasi dan juga biaya konsumsi.

\section{TINJAUAN PUSTAKA}

Penelitian sebelumnya pernah dilakukan oleh Zaky Nur Fajri (2012), dari Universitas Muhammadiyah Surakarta dengan judul "Aplikasi Online Wedding Organizer Berbasis Web Menggunakan PHP dan MYSQL". Pembuatan Aplikasi Online Wedding Organizer Berbasis Web Menggunakan PHP dan MYSQL menggunakan metode study literatur, pengumpulan data, dan analisa data dan perancangan. Dari metode tersebut dibuatlah suatu Aplikasi Online Wedding Organizer Berbasis Web yang bertujuan untuk membantu mengambil keputusan dalam hal resepsi pernikahan, Aplikasi Online Wedding Organizer Berbasis Web ini dapat memberikan kemudahan dalam pemesanan paket secara online, baik paket yang telah ditentukan maupun pilihan secara manual dan otomatis. Pembuatan aplikasi ini menggunakan bahasa pemrograman PHP dengan MYSQL sebagai database. Keluaran yang dihasilkan dalam penelitian tersebut adalah memberikan kemudahan bagi pelanggan yang ingin memesan paketan wedding melalui online, dan bisa dilakukan secara manual ataupun otomatis.

Peneliti yang dilakukan oleh Tioriste Siregar (2012), dari Politeknik Telkom Bandung dengan Judul "Aplikasi Wedding Organizer Berbasis Web (Studi Kasus : Avqa Keyuaza Wedding Organizer)" Permasalahan yang ada pada saat ini yaitu sistem pemesanan yang dilakukan oleh Avqa Keyuaza Wedding Organizer ini masih dilakukan secara manual yaitu via telepon. karena inilah yang telah mendasari penulis dalam pembuatan Proyek Akhir dengan judul Aplikasi Wedding Organizer Berbasis $\mathrm{Web}$, penulis dengan ini bermaksud untuk membantu pihak penyelenggara pernikahan dalam penyampaian informasi yang lebih efisien. Salah satu penggunaan teknologi informasi adalah aplikasi berbasisweb yang dibangun menggunakan PHP dan MySQL. Aplikasi ini dibuat dengan menggunakan codeigniter framework yang berbasis website dengan pemrograman PHP. Codeigniter mempunyai banyak kelebihan seperti mendukung MVC model, ringan, dan lainnya. Keluaran yang terdapat pada penelitian adalah aplikasi ini diharapkan dapat mendukung kegiatan operasional wedding organizer seperti pengelolaan informasi, laporan pemesanan dan pemesanan secara online yang dapat dilakukanoleh customer wedding organizer serta memiliki fungsi yang memungkinkan bagi pihak admin untuk mengupdate informasi.

Peneliti yang dilakukan oleh Muhammad Azam Ragil Tri Putranto (2013), dari Universitas Stikubank Semarang dengan judul "Sistem Informasi Persewaan Wedding Organizer Berbasis Web". Sistem informasi persewaan Wedding Organizer yang dibuat dengan memanfaatkan teknologi informasi berbaris web, dengan tujuan umtuk memperluas area promosi dan penjualan paket pernikahan dan mempermudah proses pemesanannya. Sistem informasi persewaan Wedding Organizer rmenggunakan bahasa pemrograman PHP dan MySQL, metode yang digunakan dalam pengembangan sistem ini yaitu menggunakan metode prototyping (analisa, design, pembuatan aplikasi, evaluasi, hasil). Keluaran selanjutnya yang didapat dari peneltian ini adalah Memberikan pelayanan promosi dan penjualan paket, dan proses pemesanan.

Peneliti terkait juga yang dilakukan oleh Euis Nurpatonah (2015), dari Universitas Komputer Indonesia Bandung dengan judul "Sistem Informasi Pemesanan Wedding Organizer Berbasis Web Pada Java Exist Management". Peneliti membuat suatu sistem yaitu, wedding organizer booking information system web. Berdasarkan penggunaan bahasa pemrograman PHP dan databse MYSQL dan menggunakan metode prototype. Sistem ini dapat digunakan secara online untuk media pemesanan dan promosi wedding organizer tersebut. Awalnya pada Java Exit Management menggunakan sistem manual dan offline, namun dengan adanya sistem tersebut bisa dioperasikan 
lewat web. Keluaran juga dihasilkan dari peneliti yaitu, Menyediakan media pemesanan dan promosi online.

\section{METODE PENELITIAN}

Metodologi penelitianmerupakan proses untuk mendapatkan data yang di inginkan untuk memperoleh dan mengembangkan pengetahuan. Peneliti kali ini menggunakan beberapa metode penelitian yaitu :

\subsection{Objek Penelitian}

Metodologi penelitian ini penulis mengambil objek penelitian pada Salaam Organizer yang dibawahi oleh salah satu perusahaan/kantor pada bidang jasa yang ada di kota Semarang.

\subsection{Jenis Data}

\section{a. Data Primer}

Yaitu data yang diperoleh secara langsung dari sumber data tersebut yang berhubungan dengan penelitian yang dilakukan, yaitu data-data yang diperoleh dari observasi dan survey atau pengamatan langsung yang digunakan sebagai bahan acuan dalam pembuatan. Penelitian Rancang Bangun Event Salaam Organizer Semarang Berbasis Web Mobile ini memperoleh data langsung dari perusahaan/kantor yang sifatnya asli data-data yang kita peroleh dan sudah diamati sejak mulai mengalami masalah,, yang nantinya menjadi acuan membuat sistem service wedding.

\section{b. Data Sekunder}

Data yang diperoleh dari data penulis dalam bentuk yang sudah jadi yang bersifat informasi dan kutipan, baik dari internet maupun literature, pustaka, jurnal yang berhubungan dengan penelitian yang dibuat. Data Sekunder yang diperoleh dalam penelitian ini yaitu berasal dari berbagai Universitas dan tentunya dengan peneliti yang berbeda, adapun dalam kutiban tersebut mempunyai kesamaan, namun tidak menutup kemungkinan adanya perbedaan pada masing-masing sistem yang dibuat.

\subsection{Metode Pengumpulan Data}

Metode pengumpulan data yang digunakan penulis dalam proses pembuatan sistem ini antara lain :

\section{Observasi}

Observasi merupakan suatu pengamatan dengan menggunakan indera penglihatan. Dalam kegiatan pengamatan, observer (pengamat) belum mengajukan pertanyaan-pertanyaan khusus yang terkait dengan masalah penelitian. Observasi dilakukan saat melihat situasi yang tidak efesien dan semuanya masih menggunakan cara manual diperusahaan/kantor Salaam Organizer. Kondisi yang demikian sangat mengeluarkan waktu, tenaga, biaya yang cukup banyak, maka dari itu perlu sistem pendukung untuk menyelesaikannya.

\section{Wawancara}

Wawancara (interview) adalah pengumpulan data dengan mengajukan pertanyaan secara langsung oleh pewawancara/pengumpul data kepada responden selanjutnya jawaban-jawaban responden dicatat atau direkam. Wawancara yang dilakukan peneliti terkait permasalahan yang dihadapi pada proses kinerja untuk pelayanan service wedding dan beberapa informasi seputar Salaam Organizer dari sisi profil, jasa yang ditawarkan, prosedur pemesanan, dll.

\section{Studi Pustaka}

Studi pustaka merupakan metode yang dilakukan dengan cara mencari dari buku - buku ilmiah, laporan penelitian, karangan-karangan ilmiah, mengenai sistem yang peneliti buat untuk Salaam Organizer Semarang.Peneliti mendapatkan studi pustaka yang ditemukan dari beberapa jurnal yang terkait dengan persamaan sistem yang dibuat untuk pelayanan pemesanan, media promosi ataupun penawaran wedding. Studi pustaka diambil dari beberapa universitas. 


\subsection{Metode Pengembangan Sistem}

Metode yang digunakan untuk membuat pengembangan sistem ini, peneliti menggunakan model Prototype. Metode prototyping adalah sistem informasi yang menggambarkan hal-hal penting dari sistem informasi yang akan datang. Prototype sistem informasi bukanlah merupakan sesuatu yang lengkap, tetapi sesuatu yang harus dimodifikasi kembali, dikembangkan, ditambahkan atau digabungkan dengan sistem informasi yang lain bila perlu. (Presman,2002). Salaam Organizer dalam hal ini sebelum membuat sistem maka perlu tahapan-tahapan antara lain : pemakai mengidentifikasi kebutuhan bisnis Salaam Organizer dan menilai kelayakan alternative solusi sistem yang dibuat, pemakain menggunakan alat pengembangan aplikasi guna untuk mendesain dan menguji dengan membuat sistem sebagai uji coba kebutuhan yang akan dipakai untuk digunakan menfasilitasi konsumen, model sistem uji coba yang dibuat akan dievaluasi dan dimodifikasi supaya dapat diterima oleh konsumen yang akan memesan jasa wedding dan yang terakhir pengguna akan menggunakan dan memelihara sistem bisnis yang diterima.

\section{HASIL DAN PEMBAHASAN}

\subsection{Hasil Pengujian Sistem}

Pengujian sistem ada beberapa tahapan atau point yang perlu diuji saat melakukan proses pemesanan dan transaksi pada jasa service wedding Salaam Organizer. Hasil pengujian sistem dapat dilihat pada tabel 1 .

Tabel 1. Pengujian Sistem

\begin{tabular}{|c|c|c|c|}
\hline No & Point yang di uji & Pengujian & Hasil \\
\hline 1 & Login admin dan konsumen & $\begin{array}{l}\text { Pengecekan admin } \quad \text { dan } \\
\text { konsumen yang sudah terdaftar }\end{array}$ & $\begin{array}{l}\text { Berasil login admin dan } \\
\text { konsumen yang sudah } \\
\text { terdaftar }\end{array}$ \\
\hline 2 & $\begin{array}{l}\text { Admin dapat melakukan } \\
\text { tambah, edit, hapus, dan } \\
\text { simpan pada data konsumen, } \\
\text { data pesanan konsumen }\end{array}$ & $\begin{array}{l}\text { Penginputan } \\
\text { konsumen, edit, hapus, simpan } \\
\text { bisa dijalankan }\end{array}$ & $\begin{array}{l}\text { Berhasil keluar output data } \\
\text { konsumen dan data pesanan }\end{array}$ \\
\hline 3 & $\begin{array}{l}\text { Admin dapat melakukan } \\
\text { tambah, edit, hapus, dan } \\
\text { simpan pada tambah, isi } \\
\text { vendor dan perlengkapan }\end{array}$ & $\begin{array}{l}\text { Penginputan vendor dan } \\
\text { perlengkapan oleh admin dapat } \\
\text { dilakukan }\end{array}$ & $\begin{array}{l}\text { Berhasil keluar output data } \\
\text { vendor dan data } \\
\text { perlengkapan }\end{array}$ \\
\hline 4 & $\begin{array}{l}\text { Admin dapat melihat arsip } \\
\text { konsumen }\end{array}$ & $\begin{array}{l}\text { Output arsip konsumen akan } \\
\text { tampil setelah konsumen telah } \\
\text { selesai melakukan transaksi } \\
\text { lunas }\end{array}$ & $\begin{array}{l}\text { Berhasil keluar output } \\
\text { otomatis setelah konsumen } \\
\text { dinyatakan telah selesai } \\
\text { dalam pemesanan }\end{array}$ \\
\hline 5 & $\begin{array}{l}\text { Admin dapat mengatur } \\
\text { jadwal pertemuan, berhak } \\
\text { atas wewenang menyetujui } \\
\text { maupun menolak jadwal }\end{array}$ & $\begin{array}{l}\text { Tampil data jadwal sesuai } \\
\text { request maupun penyaranan } \\
\text { request }\end{array}$ & $\begin{array}{l}\text { Berhasil melakukan edit, } \\
\text { rubah, hapus }\end{array}$ \\
\hline 6 & Admin dapat melihat Rating & $\begin{array}{l}\text { Sifatnya hanya melihat dan } \\
\text { memantau rating }\end{array}$ & $\begin{array}{l}\text { Berhasil melihat hasil rating } \\
\text { yang diberikan konsumen }\end{array}$ \\
\hline 7 & $\begin{array}{l}\text { Konsumen pada menu } \\
\text { pesanan }\end{array}$ & $\begin{array}{l}\text { Konsumen hanya bisa melihat } \\
\text { menu pesanan yang sudah } \\
\text { direquest melalui admin }\end{array}$ & $\begin{array}{l}\text { Berhasil melihat outpun } \\
\text { pesanan konsumen dan } \\
\text { detail pesanan }\end{array}$ \\
\hline
\end{tabular}




\begin{tabular}{|l|l|l|l|}
\hline 8 & $\begin{array}{l}\text { Konsumen pada menu } \\
\text { pembayaran }\end{array}$ & $\begin{array}{l}\text { Konsumen bisa melakukan } \\
\text { transaksi pembayaran atau } \\
\text { confirm payment untuk } \\
\text { melunasi pesanan yang sudah } \\
\text { dipesan }\end{array}$ & $\begin{array}{l}\text { Berhasil melihat update } \\
\text { pembayaran yang sudah } \\
\text { diunggah disistem }\end{array}$ \\
\hline 9 & Konsumen atur jadwal & $\begin{array}{l}\text { Konsumen dapat melakukan } \\
\text { request kepada admin untuk } \\
\text { jadwal pertemuan untuk rapat }\end{array}$ & $\begin{array}{l}\text { Berhasil mengeluarkan } \\
\text { output request data jadwal } \\
\text { pertemuan }\end{array}$ \\
\hline 10 & Konsumen pada menu Rating & $\begin{array}{l}\text { Konsumen dapat memberikan } \\
\text { rating terhadap kepuasan pada } \\
\text { pelayanan salaam organizer }\end{array}$ & Berhasil memberikan rating \\
\hline 11 & Konsumen pada menu profile & $\begin{array}{l}\text { Konsumen mengedit photo } \\
\text { profile dan melihat data } \\
\text { pribadi andian }\end{array}$ \\
\hline
\end{tabular}

\subsection{Hasil Pembahasan Pengujian Sistem}

Pada tahapan ini dilakukan proses pengujian yang di lakukan oleh admin maupun konsumen terhadap sistem yang sudah sesuai hasil yang diharapkan.

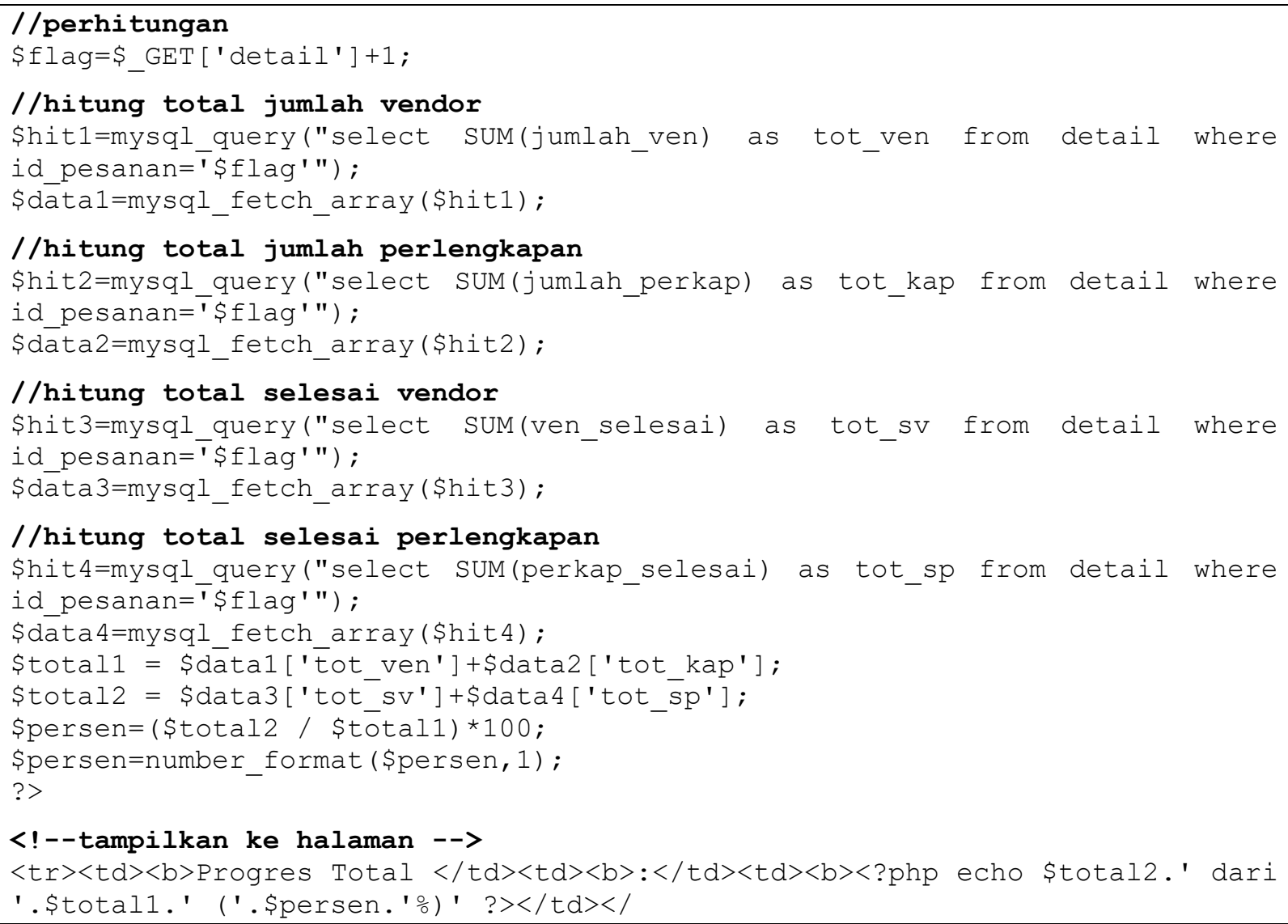

Code pada menu konsum.php

Dibuktikan dengan rumus bobot pekerjaan proyek :

- Bobot pekerjaan $=($ harga pekerjaan/harga total proyek $) \times 100 \%$

- Bobot prosentase pekerjaan = (harga yang sudah dikerjakan/harga total proyek $) \times 100 \%$ 
Pembuktian :

Keperluan : 1311 item global

Tersedia : 3 item ?

Penjelasan :

- soundsytem 200

- gedung 100

- rias 300

- catering 500 (ke- banyak)

Total keseluruhan $100 \%$

Jika kita memesan 500 (catering) berati 1311-500 = 811:1311 =0,61 (padahal catering sudah mengerjakan banyak hal missal : pemesanan buffet, pondokan, es nama, dll kita hanya dihargai kinerja $0,61 \%$ saja (item besar)

Sedangkan rias kita memesan 1 item (sudah termasuk jumlah, siapa yg dirias, namanya siapa saja, pakaian adat apa, warna apa) berate 1311-1=1310:1311 =0,99\% (padahal kita hanya memesan item kecil) dan hasil pembuktian bisa dilihat pada Gambar 1.

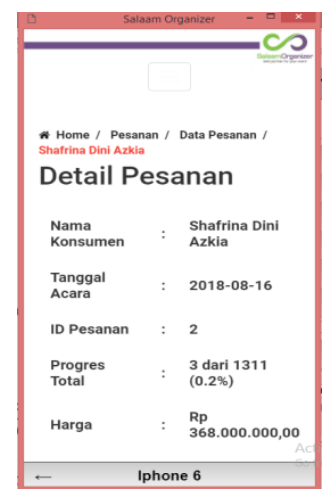

Gambar 1. Detail Pesanan

\section{KESIMPULAN}

a. Sistem akan membantu memudahkan client untuk komunikasi, memantau dan melakukan transaksi pembayaran secara online.

b. Pesanan dapat dilihat lewat smartphone, riwayat, dan catatan yang penting dapat dilihat tanpa harus melakukan pertemuan tiap saat antara client dan pihak service wedding.

c. Perancangan sistem menggunakan Star UML, implementasi sistem menggunakan pemrograman PHP dan database MYSQL yang terdiri dari 9 tabel yaitu tabel admin, tabel detail, tabel jadwal, tabel konsumen, tabel perlengkapan, tabel pesanan, tabel rating, tabel request, tabel vendor.

d. Pemilihan Metode Breakdown and Weighted ini menjadi solusi untuk mempermudah dalam memecahkan masalah untung perhitungan perincian dan pembobotan pada progress administrasi di Salaam Organizer Semarang.

\section{DAFTAR PUSTAKA}

[1] Abdul Kadir. 2003. Dasar Pemprograman Web Dinamis Menggunakan PHP. Andi Offset. Yogyakarta.

[2] Aditya, Alan Nur.2010. Jago PHP dan MySQL. Jakarta: Dunia Komputer.

[3] Aji Supriyanto (2005:238), Pengertian Sistem, Ekosiana. Yogyakarta.

[4] Aji Supriyanto. (2005). Pengantar Teknologi Informasi. Jakarta: Salemba Infotek.

[5] Bambang Prasetyo, Lina Miftahul Jannah. 2005. Metode Penelitian Kuantitatif:Teori dan Aplikasi. Jakarta: Penerbit PT.Raja Grafindo Persada. 
[6] Fajri, Zaky Nur, (2012). Aplikasi Online Wedding Organizer Berbasis Web Menggunakan PHP dan MYSQL. Tugas Akhir. Universitas Muhammadiyah Surakarta.

[7] Jogiyanto HM, 1995, Analisis dan Disain Sistem Informasi : Pendekatan Terstruktur Teori dan Praktek Aplikasi Bisnis, Andi Offset, Yogyakarta.

[8] Muhammad, Reno Harahap, (2014). Perkembangan Mobile Application di Era Modern. Penelitian, Binus University Jakarta.

[9] Nurpatonah, Euis (2015), Sistem Informasi Pemesanan Wedding OrganizerBerbasis Web Pada Java Exist Management. Skripsi. Universitas Komputer Indonesia Bandung.

[10] Putranto, Muhammad Azam Ragil Tri(2013).Sistem Informasi Persewaan Wedding Organizer Berbasis Web. Skripsi. Universitas Stikubank Semarang.

[11] Roger, S. Pressman, Ph.D. , 2012, Rekayasa Perangkat Lunak (Pendekatan Praktisi) Edisi 7 : Buku 1 ", Yogyakarta: Andi.

[12] Siregar, Tioriste (2012). Aplikasi Wedding Organizer Berbasis Web (Studi Kasus : Avqa Keyuaza Wedding Organizer). Skripsi. Politeknik Telkom Bandung.

[13] Sri Dharwiyanti, Romi Satria Wahono, (23 juni 2015), "Pengantar Unified Modeling Language(UML)",[online],2003,Available:http://rosnigj.staff.gunadarma.ac.id/Downloads/files/1 4321/10.+Unified+Modeling+Languag e.pdf. 